\title{
Android based application for visually impaired using deep learning approach
}

\author{
Haslinah Mohd Nasir'1, Noor Mohd Ariff Brahin², Mai Mariam Mohamed Aminuddin², \\ Mohd Syafiq Mispan ${ }^{4}$, Mohd Faizal Zulkifli ${ }^{5}$ \\ ${ }^{1,2,4,5}$ Fakulti Teknologi Kejuruteraan Elektrik dan Elektronik, Universiti Teknikal Malaysia Melaka, Malaysia \\ ${ }^{3}$ Fakulti Kejuruteraan Elektronik dan Kejuruteraan Komputer, Universiti Teknikal Malaysia Melaka. Malaysia
}

\section{Article Info}

Article history:

Received Dec 10, 2020

Revised Jul 8, 2021

Accepted Aug 29, 2021

\section{Keywords:}

Aided engineering

Android application

Convolution neural network

Deep learning

Visually impaired

\begin{abstract}
People with visually impaired had difficulties in doing activities related to environment, social and technology. Furthermore, they are having issues with independent and safe in their daily routine. This research propose deep learning based visual object recognition model to help the visually impaired people in their daily basis using the android application platform. This research is mainly focused on the recognition of the money, cloth and other basic things to make their life easier. The convolution neural network (CNN) based visual recognition model by TensorFlow object application programming interface (API) that used single shot detector (SSD) with a pretrained model from Mobile V2 is developed at Google dataset. Visually impaired persons capture the image and will be compared with the preloaded image dataset for dataset recognition. The verbal message with the name of the image will let the blind used know the captured image. The object recognition achieved high accuracy and can be used without using internet connection. The visually impaired specifically are largely benefited by this research.
\end{abstract}

This is an open access article under the CC BY-SA license.

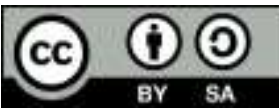

Corresponding Author:

Haslinah Mohd Nasir

Fakulti Teknologi Kejuruteraan Elektrik dan Elektronik

Universiti Teknikal Malaysia Melaka

Hang Tuah Jaya, 76100 Durian Tunggal, Melaka, Malaysia

Email: haslinah@utem.edu.my

\section{INTRODUCTION}

According to 2018 statistics from world health organization (WHO), at least 2.2 billion people from all over the world have vision impairment [1]. The visually impaired people face a lot of problems in their daily life. These people have difficulties to recognize and differentiate the objects around them thus they only rely on the guidance to help them especially for daily task. The most challenging for visually impaired are that the ability of them to recognize the colour, shape and differentiate the currency of the money. Nowadays, there are many of assistive technology that can help them as a sighted guidance and improves the quality life of visually impaired [2], [3]. The assistive technology based on computer is expected to help on the visually impaired daily task. It can be screen reading software, magnification software, dictation software, refreshable Braille displays, optical character recognition (OCR) systems, and many more [4]. The assistive technology growth from the simple technology devices to the sophisticated high technology solution using [5]-[7].

The visually impaired mostly now have the smartphone as it become a basic necessity of each individual. Thus, it provides a great platform to develop an application specifically for visually impaired to assist them. A survey done by Nora and the team have found that the person with visual impairments are 
frequently used the mobile application for their daily activities [8]. Furthermore, they are looking for some improvement and new application that can help them to less dependent on others. An experimental study has been done by Manduchi on the specific mobile task as such landmark detection using the mobile phone. His findings become the platform on designing the technology that facilitates visually impaired [9].

Many studies have developed the assistive technology using android application which useful in today world and people with visually impaired can make use of this technology to help them accomplished on their daily routine. Tharkude et al. [10] and Parkhi et al. [11], the authors proposed a smart android application for blind people with the use of object detection. The developed apps are using mobile video camera to know the direction of object, voice instructions for current locations and directions as well as to gives warning of the obstacles in front of the user [10]. While in [11], the authors design an object detection from imaged captured by smartphone's camera. The performance of the apps is quite good however it is depending on the quality of the inbuilt camera of the smartphone. Kadam et al. [12], the authors designed an apps providing with the speech output for the objects detected by using ANN classification approach. However, the apps may give variable accuracy and still need improvement to be more efficient. Other than that a mobile application called Intelligent Eye with features of light, colour detection and object, banknote recognition is developed by using image deep learning, CNN architecture [13]. The survey of User acceptability test has been done and the results show that the apps is good in general and well accepted.

Deep learning has outstanding performance and provide high quality intelligent services on mobile devices applicationss. It is mainly applied to image and voice processing at can be empower more to make people's daily life more convenient [14]. Deep learning approach such as CNN model is knownly a method that provides high accuracy in image classification [15]. It provides numerical results between 0 and 1 which obtained faster and higher accuracy values for classification purposes.

This paper proposed mobile application through deep learning approach specifically by convolution neural network (CNN) that might help the visually impaired on their daily lives. The training set for CNN is developed at Google Dataset which is developed by Google for Big Data Analytics. CNN needs the cloud storage that able to analyse the big data analysis for decision making, classification, prediction with high accuracy [16]. The proposed application doesn't require internet connection to operates and it consists of three types of detection as mentioned in Methodology section. The developed application allows the visually impaired to capture things around them with their own smartphone and will help them recognize the captured object. This will make their life easier without depending to the people around them who somethimes insincere and just take advantage on them.

This paper is organized as: section 2 describes the method used to develop the application. The results and discussion will be covered in section 3 and finally in section 4 will conclude and mentions the future recommendation.

\section{RESEARCH METHOD}

\subsection{Overview of the application}

In the phase of android mobile application development, the various useful assistant are combined in single application as:

a. Object detection: it works on the image captured by the mobile phone's camera. It will be trained with the database objects to identify the image. It helps the person with visually impairment to find their items.

b. Colour detection: it works on the image taken which the colour name is based on the RGB values of the detected image. This feature may help in their daily routing such as cloth colour and shoe selection.

c. Currency note detection: The image taken from the camera will be compared with the trained dataset for recognition. This will help visually impaired people from being cheated by others.

The features of the application are associated with audio output of verbal message for user notification as it is important for visually impaired person to identify the object [17]-[19]. Overal, this application features include:

a. Android based mobile application that can be accessed at anytime and anymwhere without internet connection. This is to ensure to secure the user personal data from third party [20], [21].

b. The input from user can be swipe gesture, and speech input which is specially designed for visually impaired for easy usage [22].

c. Incorporated with deep learning, $\mathrm{CNN}$ for fast and accurate image processing for detection and prediction.

d. The application consists of three different modes, object detection, colour detection and currency detection. The user can anaytime turning the mode by swiping or voice input.

e. Incorporated with output of verbal message to notify the user on the identified objects.

Int J Artif Intell, Vol. 10, No. 4, December 2021: 879 - 888 
Figure 1 shows the flowchart of the application on how it operates from starting the application is ready to use by the user. It started with the Main menu which consists of three different modes where the user can choose by click the menu or by the speech voice input. The camera will automatically on, and the user can capture the image for detection and prediction using CNN model. The application will notify the user through the audio output.

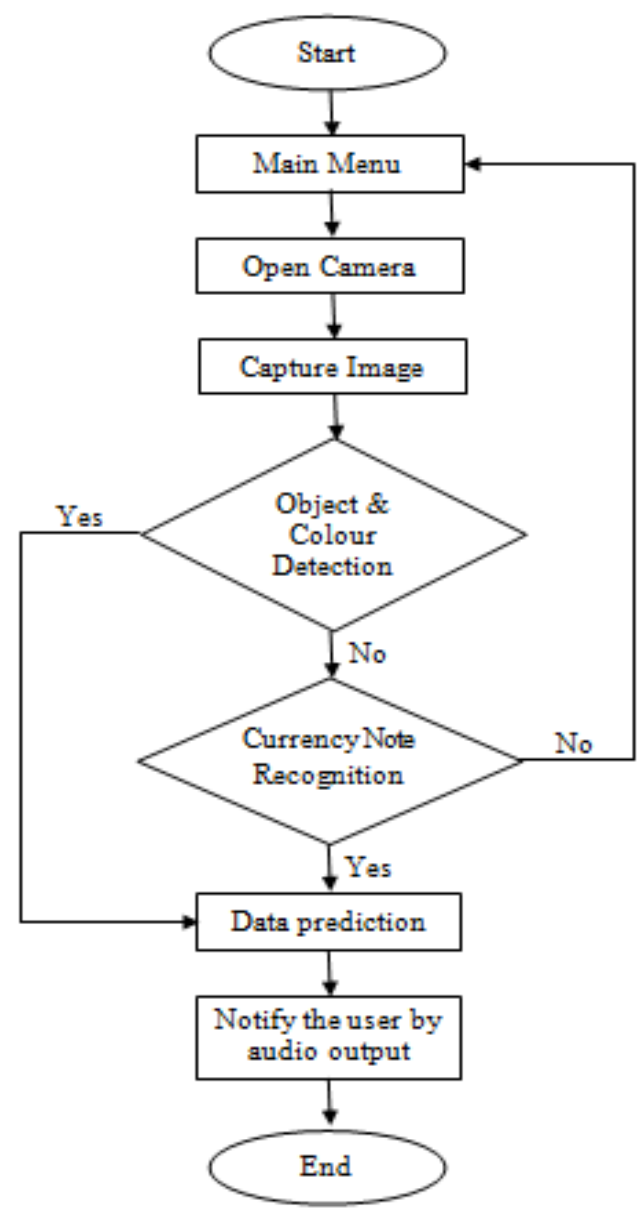

Figure 1. Flowchart of the android application system

\subsection{Application architecture}

The application is mainly developed by Android Studio and being configured by a TensorFlow Object Detection API for object detection and recognition by using CNN model. The CNN is adapted for data training approach which uses single shot detector (SSD) with a pre-trained model from MobileNet V2 which developed at Google dataset. Basically, the image captured by the user's mobile phone will be compared with the pre-trained image in database. The image loaded by the camera will be extracted and classified through the prediction prosess using TensorFlow algorithm. The application will notify the user through the audio output with the predicted image. Figure 2 shows the application architecture in general.

TensorFlow is an end-to-end open source deep learning models developed by Google that can be deployed into a mobile or embedded devices. It has greatly easier model building with intuitive high level APIs which makes it for immediate easy debugging for any application. TensorFlow also provides a platform to excute machine learning algorithms which can be carried in wide range of heterogeneous systems from mobile phone to large scale of systems. The models can be train easily and accelerates the application of CNN due to the optimization of GPU usage [23].

The block diagram involved in image classification using the TensorFlow is shown in Figure 3. The data set are stored in IDX format with image and label information for both data test testing and training.

In this paper, the data set contains about 1000 training image for 1 testing data. So grossly, there are almost 50,000 training image for 50 testing data with different situation of images. This is to make sure that 
the image classification will produce high accuracy. In the second stage of designing the algorithm of CNN model using TensorFlow, the parameter with 10,000 iterations were processed with different epochs. The results of the training accuracy for 10 and 100 epochs are shown in section 4. In last stage for image classification performance, the different images were testing, and the accuracy percentage based on CNN image classification were calculated.

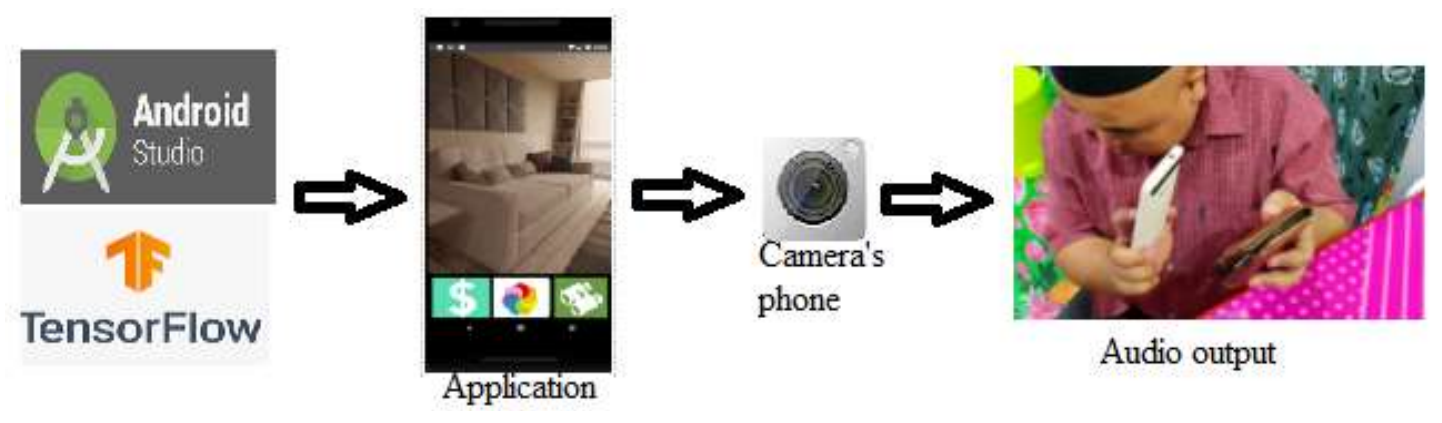

Figure 2. Application architecture

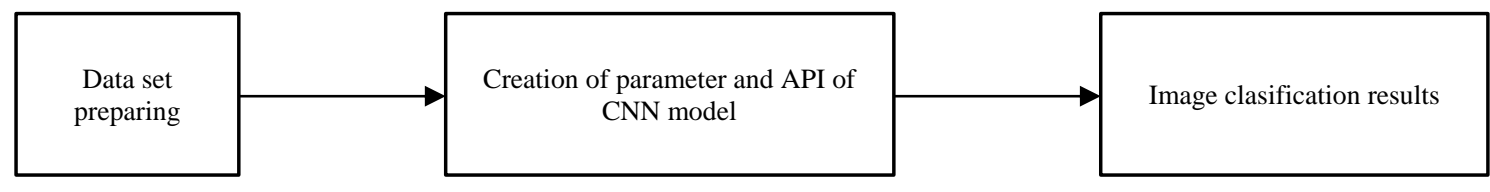

Figure 3. Proposed block diagram of utilizing CNN by TensorFlow

\section{RESULTS AND DISCUSSION}

\subsection{Object detection and recognition classifier training}

In prior of object detection and recognition development, the classifier training accuracy analysis is a must step to make sure that the application provides high accuracy percentage. About 250 images for each class is collected with variety of backgrounds, orientation and conditions. The images will be trained with different epoch to see the training and validation accuracy. Figure 4 and Figure 5 show the training and accuracy result using 10 and 100 epochs respectively.

As can be seen from both Figure 4 and Figure 5, the highest value of accuracy is 1.0 while the highest value for validation is 0.717 at 100 epochs. Based on the results, it clearly shows that the more epochs are, the highest value of validation accuracy can be achieved.

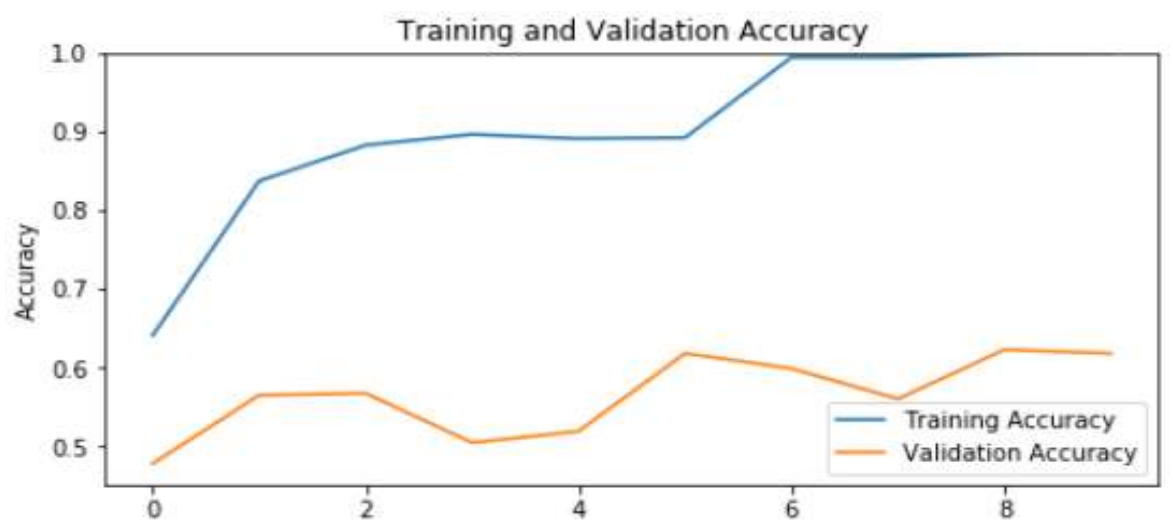

Figure 4. The training and validation accuracy based on 10 epochs 


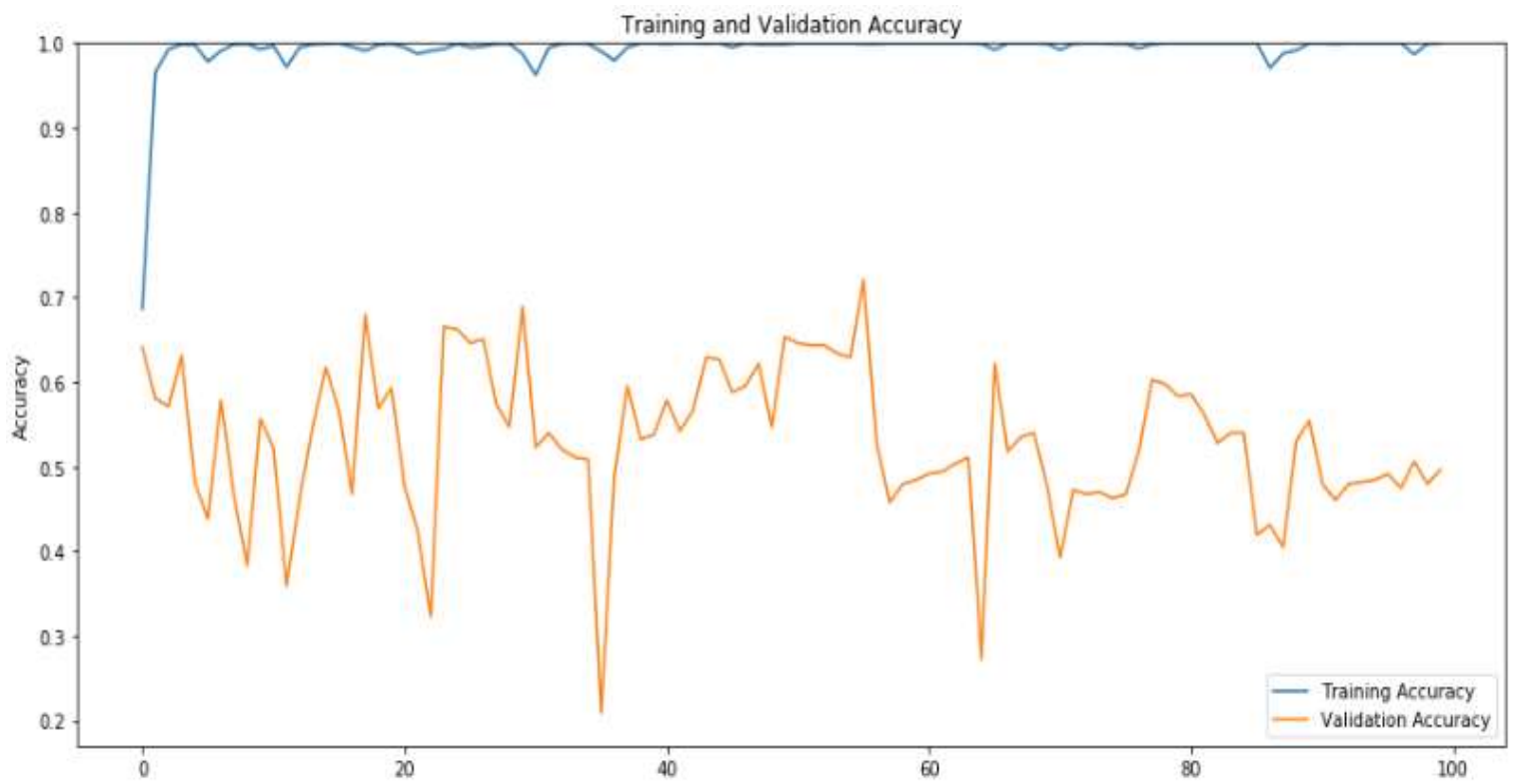

Figure 5. The training and validation accuracy based on 100 epochs

\subsection{Application testing}

The application is design with simple interface to make it user friendly for visually impaired. It contains with 3 menu buttons, currency note detector, colour detector, and explore things as object detector as shown in Figure 6. The menu can be selected by touching the screen or use talkback function.

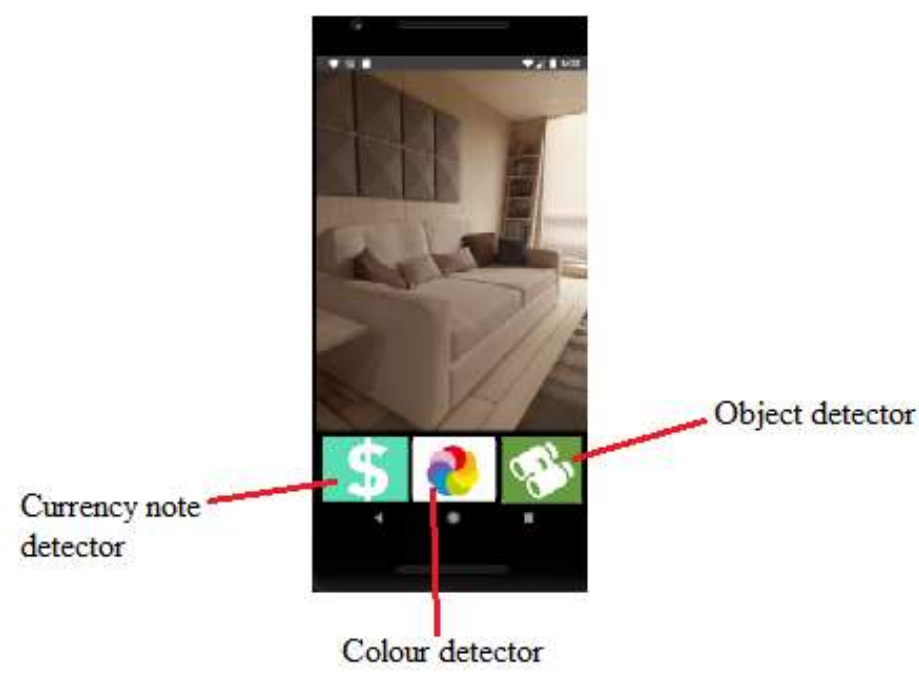

Figure 6. User interface design of android application

The application is tested in real time with currency note and colour detection. The results with the accuracy percentage are presented in Table 1 and Table 2. Based on the both tables, the detection accuracy is relatively good with high confidence and accuracy level. The application is able to detect the image captured with high accuracy. 


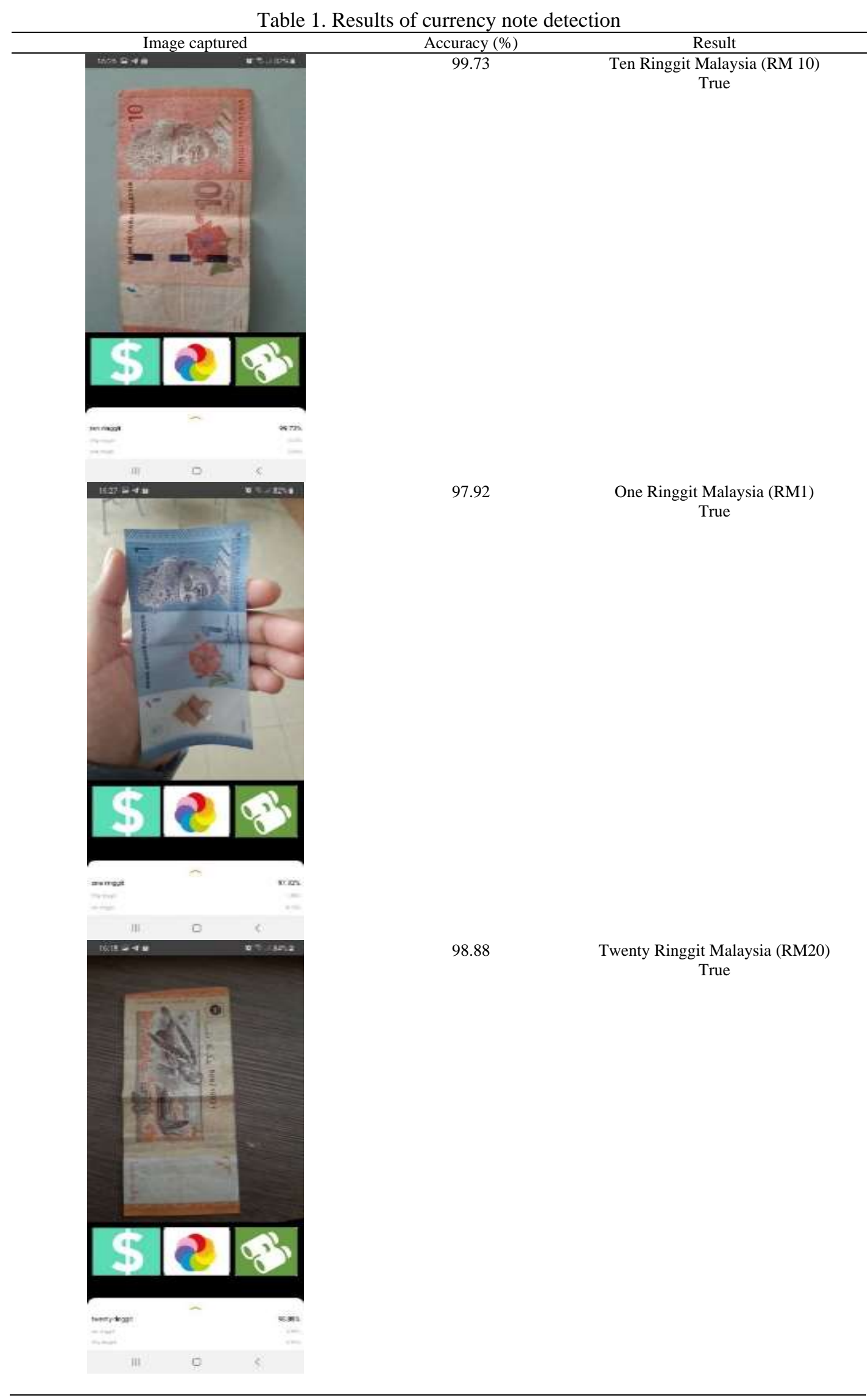

Int J Artif Intell, Vol. 10, No. 4, December 2021: 879 - 888 
Table 2. Results of colour detection

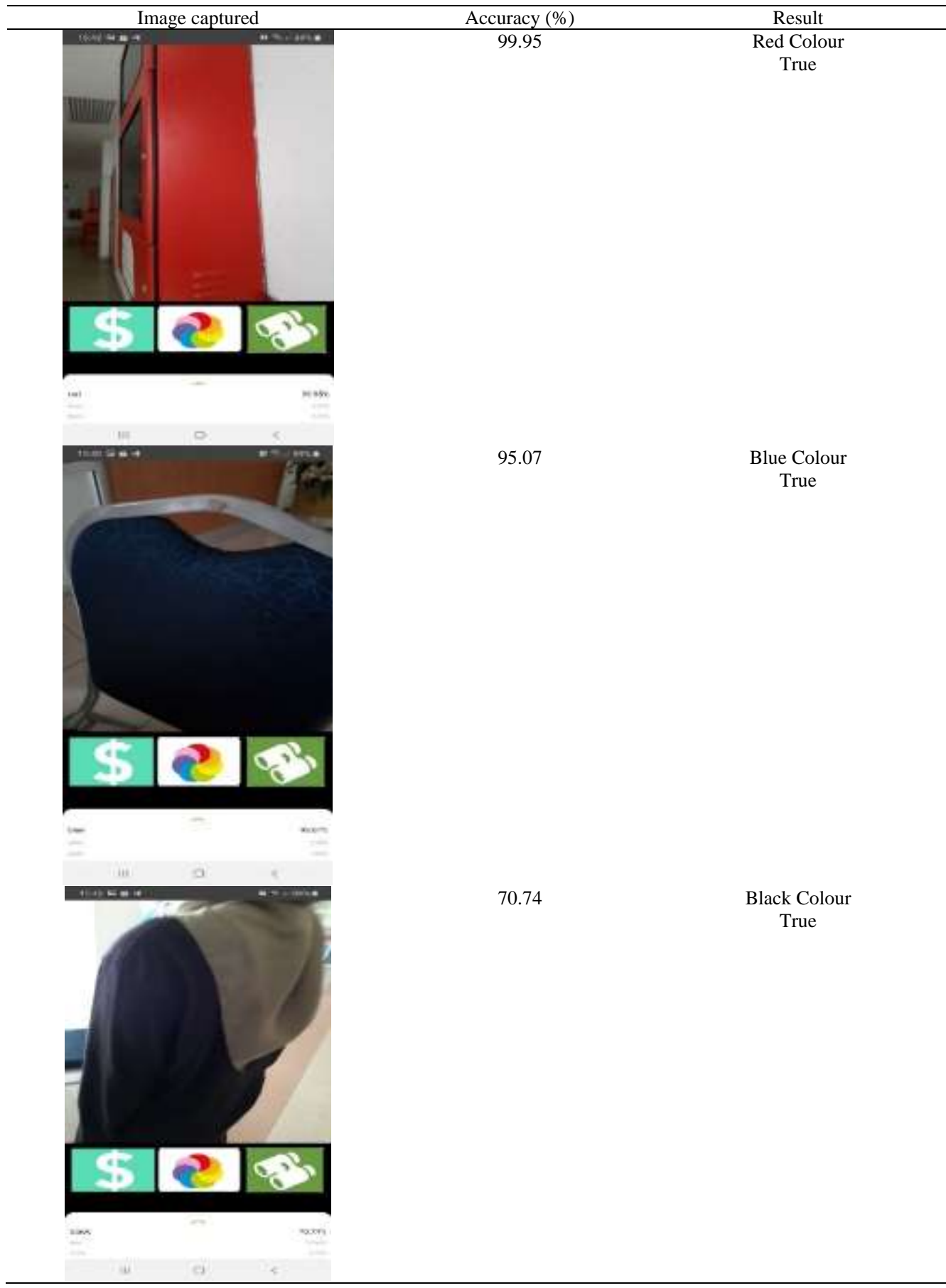

\subsection{Site testing implementation}

The site testing application is implemented with the real subject, the people with visually impaired at the reflexology centre in Melaka Mall. Before they use the application, the demonstration with explanation was done. As they are totally cannot see, the talkback function is used as the input for menu selection. Figure 7 shows the photo of the subject use the application by themselves.

The feedback from them was taken after the testing. They are very excited with the application as the application is able to detect things in front of them accurately and effectively. The feature in this application are really needed by them and hoping that they can be more accessible to their surroundings. 

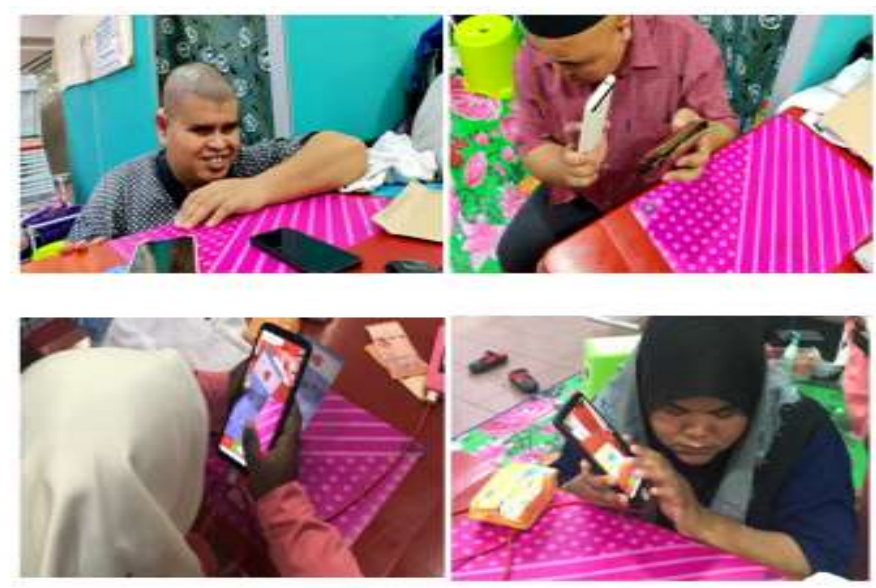

Figure 7. The photo taken during the site testing implementation

\subsection{Comparison to the other application}

B. S. Lin et al. has proposed computer image recognition as guided system which recognize multicle obstacels in every image using CNN algorithm. The accuracy of recognition is reached only 60\% [24]. Other applications presented by Anitha which focus on real time object detection has achieved upto $92.16 \%$. It is quite efficient with that number of image classification accuracy percentage [25]. However, compared to other applications, the proposed application in this paper is considered has higher accuracy in image classification. The accuracy of the proposed application is up to $99.95 \%$. The novelty of this application compared to the existing are:

a. An assistive mobile application to help make the world more accessible to the visually impaired people which using deep learning approach to process image from phone's camera to do image classification

b. This application is able to give fast and more accurate results because it is using on device image recognition from deep learning approach

c. As it using on device image recognition, no internet connection is required. So the user can use the application at anywhere and anytime

d. Additionally, with no internet connection required the personal data is safe and secure. There will be no $3^{\text {rd }}$ party involves in retrieving the data

e. The application is user friendly. The application only consists of simple interface with no distraction from complicated settings so that it can be easily been used by the visually impaired

\section{CONCLUSION}

This paper has presented the development of android application for people with visually impairment with some novelty compare to the existing application. Based on the results, the application is able to predict the image captured by the user with high accuracy up to $99.95 \%$. On top of that, the site testing with visually impaired people has been done with positive feedback received. As for future work, the additional feature can be added as well as the inclusion of internet of things (IoT) for more advance application.

\section{ACKNOWLEDGEMENTS}

The authors would like to thanks to the Universiti Teknikal Malaysia Melaka for the support received in the accomplishment of this work. Not forgotten, a special thanks to the people with visually impaired at the reflexology centre in Melaka Mall, Melaka, Malaysia.

\section{REFERENCES}

[1] https://www.who.int/en/news-room/fact-sheets/detail/blindness-and-visual-impairment [Online] Accessed on 5 October 2020.

[2] https://www.afb.org/blindness-and-low-vision/ [Online] Accessed on 3 Mac 2021.

[3] https://guides.library.illinois.edu/blind/visualimpairment [Online] Accessed on 3 Mac 2021.

[4] https://www.miusa.org/resource/tipsheet/assistivetechnologyforblind [Online] Accessed on 3 Mac 2021. 
[5] A. Bhowmick and S. M. Hazarika, "An insight into assistive technology for the visually impaired and blind people: state of art and future trends," Journal on Multimodal User Interfaces, Vol.11, No.2, pp.1-24, 2017, DOI:10.1007/s12193-016-0235-6.

[6] Y. Rosner and A. Perlman, "The effect of the Usage of Computer-Based Assistive Devices on the Functioning and Quality of Live of Individuals who are Blind or have low vision," Journal of Visual Impairment \& Blindness, Vol.112, No.1, pp.87-99, 2018, DOI:10.1177/0145482X1811200108.

[7] J. Hwang, K. H. Kim, J. G. Hwang, S. Jun, J. Yu and C. Lee, "Technological Opportunity Analysis: Assistive Technology for Blond and Visually Impaired People," Sustainability, Vol.12, No.20, pp.8689, 2020, DOI:10.3390/su12208689.

[8] N. Griffin-Shirley, D. R. Banda, P. M. Ajuwon, J. Cheon, J. Lee, H. Ran Park, and S. N. Lyngdoh, "A Survey in the use of mobile applications for people who are visually impaired," Journal of Visual Impairement \& Blindness, CE Article, pp.308-323, 2017, DOI:10.1177/0145482X1711100402.

[9] R. Manduchi, "Mobile vision as Assistive Technology for the Blind: An Experimental Study," Lecture Notes in Computer Science, Vol. 7383. Pp.9-16, 2012.

[10] K. B. Tharkude, A. K. Wayase, P. S. More, and S. S. Kothey, "Smart android application for blind people based on object detection," International Journal of Innovative Research in Computer and Communication Engineeting, Vol.4, No.4, pp.5149-5155, 2016, https://doi.org/10.17762/ijritcc.v3i10.4979

[11] S. Parkhi, S. S. Lokhande, and N. D. Thombare, "Vocal vision android application for visually impaired person," International Journal of Science, Engineering and Technology Research, Vol.5, No.6, pp.2233-2239, 2016.

[12] A. J. Kadam, S. Awate, S. Desai, R. Khese, and G. Patange, "Android application for visually impaired users," Imperial Journal of Interdisciplinary Research, Vol.3, No.2, pp.1674-1677, 2017.

[13] M. Awad, J. El Haddad, and E. Khneisser, "Intelligent Eye: A mobile application for assisting blind people," in IEEE Middle East and North Africa Conference. pp1-6, 2018, DOI:10.1109/MENACOMM.2018.8371005.

[14] J. Wang, B. Cao, P. S. Yu, L. Sun, W. Bao and X. Zhu, "Deep Learning Towards Mobile applications," 2018 IEEE $38^{\text {th }}$ International Conference on Distributed Computing Systems, pp.1385-1393, 2018, DOI:10.1109/ICDCS.2018.00139.

[15] D. Choe, E. Choi and D. K. Kim, "The Real-Time Mobile Application for Classifying of Endangered Parrot Species using the CNN Models Based on Transfer Learning," Deep Learning in Mobile Information Systems, Vol.2020, pp.1-13, 2020, DOI:10.1155/2020/1475164.

[16] M. M. Najafabadi et al., "Deep learning applications and challenges in big data analytics," Journal of Big Data, Vol.2, No.1, pp.1-21, 2015, https://doi.org/10.1186/s40537-014-0007-7.

[17] A. Csapo, G. Wersényi, H. Nagy, and T. Stockman, "A survey of assistive technologies and application for blind users on mobile platforms: A review and foundation for reserch," Journal Multimodal User Interface, Vol.9, pp.275-286, 2015, https://doi.org/10.1007/s12193-015-0182-7.

[18] C. Willings, "Auditory Access Device" [Online] Available in teachingvisuallyimpaired.com. [Accessed on 5 October 2020].

[19] P. Lavanya, S. Nandhini, V. Hemalatha, and P. Gomathi, P., "Currency pinpointing through mobile application for visually impaired people," International Research Journal of Engineering and Technology, Vol.6, No.3, pp.17961798, 2019.

[20] R. Balebako, A. Marsh, J. Lin, J. Hong and L. F. Cranor. "The Privacy and Security Behaviors of Smartphone App Developers," Conference: Workshop on Usable Security, pp.1-10, 2014, DOI:10.14722/usec.2014.23006.

[21] P. Weichbroth and L. Lysik, "Mobile Security: Threats and Best Practices," Mobile Information System, Vol.2020, pp.1-15, 2020, DOI:10.1155/2020/8828078.

[22] R. Sayal, C. Subbalakhmi and H. S. Saini, "Mobile App Accessibility for Visually Impaired," International Journal of Advanced Trends in Computer Science and Engineering, Vol.9, No.1, pp.182-185, 2020, DOI:10.30534/ijatcse/2020/27912020.

[23] M. Abadi et al., "TensorFlow: A system for large-scale machine learning," Proceedings of the $12^{\text {th }}$ USENIX Symposium on Operating Systems Design and Implementation (OSDI'16), pp. 265-283.

[24] B. S. Lin, C. C. Lee and P. Y. Ching, "Simple Smartphone-Based Guiding System for Visually Impaired People," Sensors, Vol. 17, pp. 1-22, 2017, DOI:10.3390/s17061371.

[25] J. Anitha, A. Subalaxmi and G. Vijayalakshmi, "Real Time Object Detection for Visually Challenged Persons," International Journal of Innovative Technology and Exploring Engineering, Vol.8, No.8, pp. 312-314, 2019.

\section{BIOGRAPHIES OF AUTHORS}

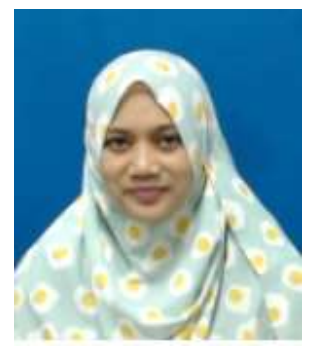

Haslinah Mohd Nasir received her Bachelor Degree in Electrical - Electronic Engineering (2008) from Universiti Teknologi Malaysia (UTM), MSc (2016) and PhD (2019) in Electronic Engineering from Universiti Teknikal Malaysia Melaka (UTeM). She had 5 years (2008-1013) experience working in industry and currently a lecturer in UTeM. Her research interest includes microelectronics, artificial intelligence and biomedical. 

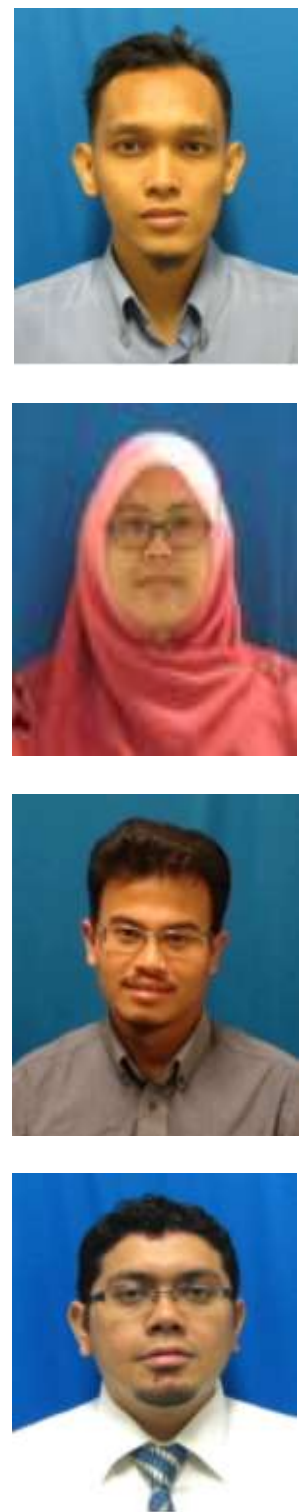

Noor Mohd Ariff Brahin received B. Eng Electrical - Electronic (Hons) from Univeristi Teknologi Malaysia (UTM) in 2008. He had experienced working in semiconductor industries as a structural design engineer from 2008 until 2013. He is currently a teaching engineer in Universiti Teknikal Malaysia Melaka. His research interests include artificial intelligence, microelectronics and IC design.

Mai Mariam Mohamed Aminuddin is a senior lecturer at Universiti Teknikal Malaysia Melaysia (UTeM) and has been worked as educator for more than 18 years. She obtained TRIZ Certificated Instructorship Level 1 from MyTRIZ in 2018. She also is a certified TRIZ Practitioner Level 3 awarded by the International TRIZ Association (MATRIZ) in 2017. Her area of expertise is artificial intelligence, biomedical engineering and TRIZ.

Mohd Syafiq Mispan received B. Eng Electrical (Electronics) and M. Eng Electrical (Computer and Microelectronic System) from Universiti Teknologi Malaysia, Malaysia in 2007 and 2010 respec- tively. He had experienced working in semiconductor industries from 2007 until 2014 before pursu- ing his Ph.D. degree. He obtained his Ph.D. degree in Electronics and Electrical Engineering from University of Southampton, United Kingdom in 2018. He is currently a senior lecturer in Fakulti Teknologi Kejuruteraan Elektrik dan Elektronik, Universiti Teknikal Malaysia Melaka. His current research interests include hardware security, CMOS reliability, VLSI design, and Electronic Systems Design.

Mohd Faizal Zulkifli received B. Eng Electrical (Hons) from Universiti Teknologi MARA in 2008. He worked as a component design engineer for 5 years prior joining Universiti Teknikal Malaysia Melaka as a teaching engineer. His research interests include ASIC physical design, Programmable Devices, and Artificial Intelligence. 